\title{
Levels of Marital Satisfaction and its Relation to Some Variables on a Sample of Women in Amman City / Jordan
}

\author{
Entisar Yousef Smadi ${ }^{1}$ \\ ${ }^{1}$ The World Islamic Science \& Education University, W.I.S.E., Amman-Jordan \\ Correspondence: Entisar Yousef Smadi, Assistant Professor. \\ Received: September 11, 2017 \\ Accepted: October 11, $2017 \quad$ Online Published: November 28, 2017 \\ doi:10.5539/ass.v13n12p103 \\ URL: https://doi.org/10.5539/ass.v13n12p103
}

\begin{abstract}
The present study aimed to identify the level of marital satisfaction among a sample of women in Amman city / Jordan, and its relation to some variables, The sample included 165 women, it was randomly selected, the researcher designed a questionnaire that measures the level of marital satisfaction, which included 20 paragraphs, each paragraph measures one dimension related to marital satisfaction, The questionnaire was applied by the study members, The statistical analysis showed: 1- The level of marital satisfaction for all members of the study was medium level of marital satisfaction. 2- No statistically significant differences in marital satisfaction due to the variable number of years of marriage. 3- No statistically significant differences in marital satisfaction due to the variable number of children.4- No statistically significant differences in the levels of marital satisfaction between working and non-working women.5There are statistically significant differences in marital satisfaction due to the variable educational level of women. 6There are statistically significant differences in marital satisfaction due to the variable family income. This is a logical consequence of the nature of the study community.

The study recommended providing preventive counseling services for young men and women before marriage, and provide counseling services for couples about mechanisms of effective marital interaction, in order to reduce the risk factors leading to marital failure.
\end{abstract}

Keywords: Marital satisfaction, women, counseling services.

\section{Introduction}

The marital relationship is the foundation upon which societies are based, The relationship is also an important link across many cultures, The marital relationship is associated with family structure, the state of stability in marital relations is linked to marital satisfaction, this led to creation of healthy families whose members are in a state of positive interaction, as a normal result of health households, social construction will enjoy high quality and stability.

Both Carandang \& Guda (2015) pointed that is marriage is generally defined as "a social contract between two individuals that unites their lives legally, economically, and emotionally" that gives legitimacy to relations within the marriage. It may also refer to the union between people, socially, and economically. Marital success is the goal and dream of every couple upon entering the married life though such is a real challenge. Thus, considering several vital factors contributing to it and gaining knowledge on how to build a strong and successful marital relationship are good starting points to achieve such goal.

Marital satisfaction is gaining increasing concern in modern society, The theory argues that people have multiple goals to achieve in their marriage. These marital goals can be classified into three categories: personal growth goals, companionship goals, and instrumental goals. The priority of the three types of marital goals is under dynamic changes across adulthood. Generally speaking, young couples emphasize the personal growth goals, middle - aged couples prioritize the instrumental goals, and old couples focus on the companionship goals. Whether the prioritized marital goals are achieved in marriage determines marital satisfaction. Other factors influencing marital satisfaction can be linked with marital goals in two ways. Some factors, such as life transitions and cultural values, can affect the priority of different marital goals; while other factors, such as communication pattern, solving problem, and attribution, can facilitate the achievement of the prioritized marital goals (Tianyuan \& Helene, 2011)

Quality of the marital relationship is an important determinant of parenting experiences in families with typically developing sons or daughters. Parents in the general population who are in well-functioning marital relationships report less parenting stress than parents in poorly functioning marital relationships. Researchers have also shown that the marital relationship "spills over" into the parent child relationship. Parents who have better quality marital relationships report better quality parent-child relationships; there is some evidence that this spillover may be particularly true for fathers. Mothers and fathers who are dissatisfied with their marriage report more parenting burden or stress than those who are satisfied with their marriage (Hartley et al, 2011)

Marriage has dimensions related to the personal level such as: feelings, communication and solving problem. Marriage also related to the social level, including the relationship with children, in addition there are impact of marriage on the 
economic level and the legal aspect, Accordingly, researchers in this field sought to study marital satisfaction and to identify some relevant variables, literature review shows that.

The importance of this study: The study was based on identifying marital satisfaction levels on a sample of women in Amman/Jordan, Where the statistical results in Jordan showed that divorce rates are increasing than in the past, resulting in many risk factors that threaten the cohesion and stability of society, and marital satisfaction is very important in the couples life, because its reflexes Adaptation, growth and sustainability of relationship, and maybe affecting on the transaction between family members, marital satisfaction helps husbands and wives to solve their problems effectively, and therefore this study is very important for considerations related to community culture, and the social context.

Purpose of the study: The study aimed to identify the levels of marital satisfaction on a sample of women in Amman / Jordan, and to identify the effect of some variables on the level of marital satisfaction, and identify risk factors threatened by the stability of the marital relationship, The study aims to answer the following questions:

\section{Study Questions}

1-What is the level of marital satisfaction on a sample of women in Amman city/Jordan?

2- Are there statistically significant differences $(\alpha=0.05)$ in the level of marital satisfaction due to the variable number of years of marriage?

3-Are there differences of statistical significance $(\alpha=0.05)$ in the level of marital satisfaction due to the variable number of children?

4-Is there a statistically significant $(\alpha=0.05)$ relationship between the work of women and their marital satisfaction?

5 -Are there differences of statistical significance $(\alpha=0.05)$ in the level of marital satisfaction due to the variable educational level of women?

6-Are there differences of statistical significance $(\alpha=0.05)$ in the level of marital satisfaction due to the variable income of the family?

The sample of this study: included 166 randomized sample women from the city of Amman, in Jordan.

\section{Literature}

A review of the literature of social and psychological researches shows that there are many studies that dealt with the subject of marital satisfaction, with differences in the study communities and the form of samples and variables that have been studied, this indicates the importance of the subject of marital satisfaction and its general impact across different cultures, following are some studies that dealt with the subject of marital satisfaction:

Carandang \& Goda (2015) prepared a study about marital satisfaction was used the Sternberg scale to measure levels of love and this is done by measuring the personal relationship, feelings and commitment of Batangas city. The survey method was by using the questionnaires and the spouse satisfaction index, and the number of respondents was 400 pairs. The results of the correlation analysis showed a positive correlation between the level of intimate relationship and the marital satisfaction of both males and females. The study showed significant differences in the level of intimacy between males by age of marriage and job status. For women, the results showed both the level of education and employment are related with levels of marital satisfaction.

On the other hand there is a Study by Abbasi \& Afsharinia (2015) aimed to identifying the relationship between the patterns of communication at couples and the level of withdrawal and their relation to marital satisfaction was completed. The sample of the study included 30 pairs of students at the Kermanshah University where the marital satisfaction questionnaire (CPQ) and (ENRICH) was applied and the Coefficient of honesty and consistency was extracted of the scales, the Pearson correlation coefficient was used to analyze the data, while the data was analyzed by SPSS software. The results showed that the highest correlation in the mutual constructive relationship and marital satisfaction among women did not show the pattern of call / pull relationship any relation to marital satisfaction, and the results showed a negative correlation between marital satisfaction and mutual contact. Men and women had similar results.s

Dabone (2014) finished study about Marital Satisfaction, aimed to know the impact of age on the level of marital satisfaction in the Municipality of the Brong - Ahafo Region of Ghana. The researcher used descriptive survey design as a research framework for the study. The study sample included 320 couples. Methodology was based on the formulation of a single research and hypothesis question. Data were collected from respondents by using the marital satisfaction list (MSI). Statistical analysis showed that both young and old married in the municipality are dissatisfied with their marriage. With a higher level of marital satisfaction for older persons compared to young persons. The study recommended the provision of counseling services for young people.

The study by Rebello et al. (2014) aimed to identifying the idea of couples about their marital relations, and specifically evaluating the marital relationship of 100 couples in Brazil. The tool of this study : Marriage and Relationship Questionnaire (MARQ). The results of the study showed that 86\% of those living together for 12.62 Year on average are satisfied with their marital relationship, and that associated with the level of jealousy, partnership and love to be the most relevant factors of marital satisfaction. 
In a study to investigate the impact of personal dimensions and their impact on marital satisfaction, Javanmard \& Garegozlo (2014) conducted a study to identify the relationship of personality exclusion (neuroticism, extraversion, openness, agreeableness and consciousness) and marital satisfaction With 35 men and 35 women, the research methodology was based on the descriptive approach. The study used NEO Five Factor Inventory (NEO-FFI) and Marital Satisfaction Inventory (ENRICH). The results of this study showed that neuroticism leads to marital dissatisfaction.

The study of Villa \& Prette (3013) in Brazil aimed to identifying the social skills of couples through the application of the social skills scale (MSSI-Villa\&Del-Prette) and Social Skills Inventory (SSI-Del-Prette), the study sample included a total of 406 married men, 188 men and 218 women. The study showed a relationship between marital satisfaction and social skills. Self-control and empathy were found to be related to marital satisfaction of men, conversation, expression and empathy related to marital satisfaction of women. This indicates gender differences regarding the importance of social skills and marital relationship.

In a study limited of women, Yadalijamaloye et al (2013) Conducted study aimed to explore the relationship between self-esteem and marital satisfaction in two cities in Iran. The sample included 757 women. 381 women in Najafabad and 376 in Fuladshahr married for at least 3 years. The results showed a relationship between the age of women and the duration of marriage on the marital satisfaction, the number of children, the duration of marriage, self-esteem and age can be predicted satisfactorily in Najaf, the number of children and self-esteem can explain marital satisfaction among women in Fuladshahr.

Bloch et al (2013) studied marital satisfaction through a longitudinal sequential study, which lasted for 13 years. age of the study sample was middle age (40-50 years) and the adult (60-70 years), who continued their marriage for many years. The study aimed at determining the methods of reducing the indicators of negative feelings after the negative events between the spouses, data analysis was performed using correlation models. The results of the study showed a decrease in negative behavior among wives with time progressing, and increase in the level of marital satisfaction, a decrease in negative behavior and use of constructive communication.

A study based on demographic variables, Zainah et al (2012) finish this study about marital satisfaction, The study was designed to determine differences in marital satisfaction based on demographic variables. The sample included 423 married couples. The Enrich scale was used to measure marital satisfaction. Statistical analysis showed statistically significant differences in the level of marital satisfaction based on the number of years of marriage and family income, The study pointed out the importance of providing marital counseling services in increasing the level of marital happiness.

\section{Method}

Tool: marital satisfaction scale, built after a review of the theoretical literature and previous studies on the subject of marital satisfaction, scale included 20 items, the scale items Reflect Networking, support and participation between spouses, Ranging answer on the scale items between 1-5 and 1 to indicate a very low degree, 2 indicate to a few degrees, 3 indicate middle, 4 refers to a large degree, 5 indicate to a very large degree.

To calculate scores, Calculated according to the following equation:

$\frac{\text { Highest rate- Minimum }}{\text { Levels }}=\frac{5-1}{3}=1.33$

Fifth Likert Scale and descriptive analysis of Response show the average between (1-2.33) Indicates a low level, (2.343.66) indicates an average level. (3.67 - 5) indicates a high level.

Factor Validity: In order to study the Factor Validity of the scale as a whole, the analysis of the data generated from the application was conducted on the sample of the study. By extracting the main components and circulating them on vertical axes. The following table shows these results:

Table 1. The underlying roots of the first four factors explain performance on the scale of marital satisfaction

\begin{tabular}{cccc}
\hline Factor & The underlying root & Explanatory Variance\% & Cumulative Explanatory Variance \% \\
\hline 1 & 9.754 & 48.768 & 48.768 \\
2 & 1.396 & 6.978 & 55.746 \\
3 & 1.111 & 5.556 & 61.302 \\
4 & 1.021 & 5.103 & 66.405 \\
\hline
\end{tabular}

The results of Table (1) indicate that there are four factors whose Eigen Value exceed (1). A total of (66.405\%) of the variance, The root value of the first factor (9.754) was explained by $(48.768 \%)$ of the variance in the scores on marital satisfaction While the Eigen Value of the second factor (1.396) was interpreted as $(6.978 \%)$ of the variation in performance on the scale of marital satisfaction, The value of the Eigen Value was (1.111) and was interpreted as (5.556\%) of the variance, The last factor was the value of the Eigen Value (1.021) and explained by (5.103\%), To verify global truth, the first Eigen Value was divided on the second Engen Value (9.754 / 1.396) and the value (6.99) was greater than (2) which clearly indicates that there is one general factor that explains most of the variation of the 
scale, Table (2) shows the saturation of the four-parameter vertex in the varimax vertical axis.

Table 2. The vertex saturation values were evaluated by the five factors obtained by the varimax vertical axis of the marital satisfaction measure

\begin{tabular}{|c|c|c|c|c|}
\hline Paragraphs. & First factor & Second factor & Third factor & Fourth factor \\
\hline 1 & .701 & & & \\
\hline 2 & .774 & & & \\
\hline 3 & .782 & & & \\
\hline 4 & .639 & & & \\
\hline 5 & & & & .588 \\
\hline 6 & & & .784 & \\
\hline 7 & & & .710 & \\
\hline 8 & & & & .778 \\
\hline 9 & & .486 & & \\
\hline 10 & & & & .658 \\
\hline 11 & .555 & & & \\
\hline 12 & & & .473 & \\
\hline 13 & & & .430 & \\
\hline 14 & & & .610 & \\
\hline 15 & & .633 & & \\
\hline 16 & & .539 & & \\
\hline 17 & & .643 & & \\
\hline 18 & & .646 & & \\
\hline 19 & & .770 & & \\
\hline 20 & & .691 & & \\
\hline
\end{tabular}

Table (2) shows that the paragraphs are saturated in one factor and this indicates a common factor that explains the variation in scores on the marital satisfaction scale

The paragraphs are distributed below:

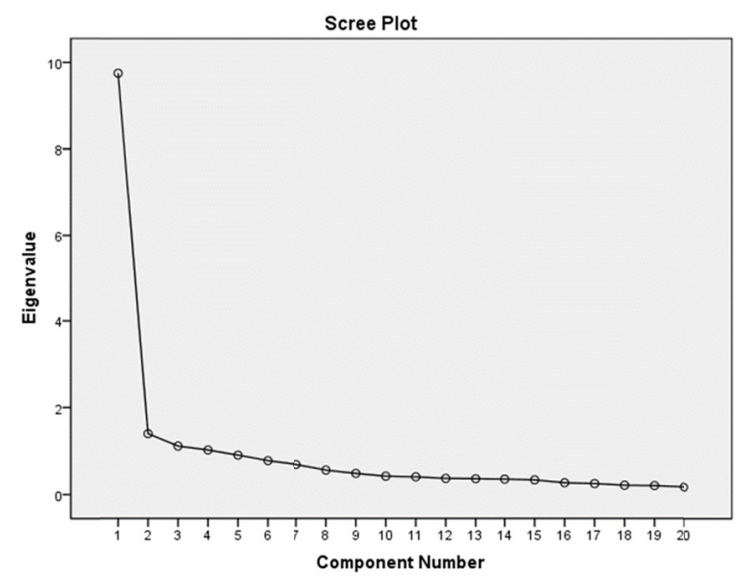

Construction Validity: Construction Validity was verified by extracting the correlation coefficient of the paragraph with the total score of the marital satisfaction scale and the following table between these results:

Table 3. The correlation coefficients of the paragraphs with the total score of the marital satisfaction measure

\begin{tabular}{cccc}
\hline Number Paragraph & Coefficient of correlation & Number Paragraph & Coefficient of correlation \\
\hline 1 & .706 & 11 & .717 \\
2 & .725 & 12 & .646 \\
3 & .727 & 13 & .682 \\
4 & .748 & 14 & .566 \\
5 & .685 & 15 & .707 \\
6 & .561 & 16 & .734 \\
7 & .660 & 17 & .633 \\
8 & .503 & 18 & .629 \\
9 & .683 & 19 & .615 \\
10 & .533 & 20 & .635 \\
\hline
\end{tabular}


Table (3) shows that the correlation coefficients of the paragraph by the overall degree of the marital satisfaction measure were all greater than $(0.3)$. The correlation coefficients ranged between $(0.503$ and 0.748$)$ and high values and indicate the construction accuracy of the scale.

Stability of the scale: The stability of the scale was verified by applying the scale to the sample of the study and the internal consistency coefficient was extracted using the Cronbach alpha formula. The value of the stability coefficient was $\alpha(0.942)$, which is high and indicates the stability of the scale.

\section{Results}

Marital satisfaction questionnaire was applied by the study members, After completion of the application process, Data were released for statistical analysis purposes, use the statistical analysis program Statistical Package for the Social Sciences (SPSS) to analyze statistical data and answer the study questions, The statistical analysis showed the following results:

1-Results related to the first question: What is the level of marital satisfaction on a sample of women in Amman city/ Jordan?

To answer this question, the averages, standard deviations and marital satisfaction were extracted on a sample of women. The following table shows these results:

Table (4) shows that the averages of the total score of the marital satisfaction measure was 3.32 and the average marital satisfaction level, while the averages for the paragraphs ranged between 2.77 and 3.85. And it show medium and high levels, where the paragraph (get my husband's sympathy with me when I get sick) ranked first with the highest mean (3.54) and high marital satisfaction. While the paragraph (My husband helps me in the housework) show last with the lowest average (2.77) and the level of marital satisfaction average.

Table 4. The averages, standard deviations and the level of marital satisfaction on a sample of women are arranged in descending order

\begin{tabular}{|c|c|c|c|c|c|}
\hline Rank & number & The phrase & average & $\begin{array}{l}\text { standard } \\
\text { deviation }\end{array}$ & $\begin{array}{l}\text { Degree of } \\
\text { direction }\end{array}$ \\
\hline 1 & 13 & I get my husband's sympathy with me when I get sick & 3.85 & 1.138 & High \\
\hline 2 & 1 & I feel comfortable with my relationship with my husband & 3.73 & 1.044 & High \\
\hline 3 & 2 & Understanding is the basis of the dealings between me and my husband & 3.65 & 1.070 & Medium \\
\hline 4 & 3 & My personal relationship with my husband is warm & 3.55 & 1.009 & Medium \\
\hline 5 & 20 & My husband appreciates the work I do & 3.54 & 1.145 & Medium \\
\hline 6 & 7 & My husband supports me with my relationships with my family & 3.53 & 1.068 & Medium \\
\hline 7 & 4 & My relationship with my husband achieved social support & 3.43 & 1.049 & Medium \\
\hline 8 & 11 & My relationship with my husband is more peaceful than the conflict & 3.43 & 1.072 & Medium \\
\hline 9 & 15 & I touch the state of constant tolerance by my husband & 3.35 & 1.102 & Medium \\
\hline 10 & 5 & $\begin{array}{l}\text { I progress socially / professionally as a result of my husband's support } \\
\text { for me }\end{array}$ & 3.31 & 1.130 & Medium \\
\hline 11 & 16 & $\begin{array}{l}\text { The most support I get in my social relationships is my husband's } \\
\text { support }\end{array}$ & 3.30 & 1.171 & Medium \\
\hline 12 & 19 & I find that my husband has qualities that fill the gaps that I suffer from & 3.26 & 1.140 & Medium \\
\hline 13 & 17 & When my husband and I disagree, we resort to dialogue & 3.19 & 1.131 & Medium \\
\hline 14 & 9 & My husband and I often agree on the way children are treated & 3.17 & 1.069 & Medium \\
\hline 15 & 18 & My husband and I exchanged courtesy & 3.12 & 1.121 & Medium \\
\hline 16 & 12 & My husband looks like a lot of things to me & 3.10 & 1.043 & Medium \\
\hline 17 & 6 & $\begin{array}{l}\text { My husband encourages me to strengthen my relationships with my } \\
\text { friends }\end{array}$ & 3.09 & 1.109 & Medium \\
\hline 18 & 10 & I share with my husband recreational activities & 3.05 & 1.298 & Medium \\
\hline 19 & 14 & My husband deals positively if I make a mistake & 2.88 & 1.237 & Medium \\
\hline \multirow[t]{2}{*}{20} & 8 & My husband helps me in the housework & 2.77 & 1.333 & Medium \\
\hline & & The overall average of marital satisfaction measure & & & \\
\hline
\end{tabular}

2-Results related to the second question: Are there statistically significant differences $(\alpha=0.05)$ on the level of marital satisfaction due to the variable number of years of marriage?

In order to answer this question, the averages and standard deviations of marital satisfaction were extracted according to the variable number of years of marriage. table (5) shows these averages:

Table (5) shows that there are apparent differences in the averages on the marital satisfaction scale according to the 
variable years of marriage. To find out the significance of these differences, a single-variance analysis test was performed. Table (6) shows these results:

Table 5. Averages and standard deviations of marital satisfaction according to the variable years of marriage

\begin{tabular}{cccc}
\hline Years of marriage & Number & Average & Standard deviations \\
\hline $1-10$ & 49 & 3.45 & .755 \\
$11-20$ & 50 & 3.21 & .768 \\
Up of 21 & 66 & 3.30 & .797 \\
\hline
\end{tabular}

Table 6. Results of the analysis of the variance of the variance to determine the significance of the differences of marital satisfaction according to the variable years of marriage

\begin{tabular}{cccccc}
\hline Source of variation & Total squares & Degrees of freedom & Average squares & (P) Value & Level of significance \\
\hline Between groups & 1.389 & 2 & .695 & 1.154 & .318 \\
Within groups & 97.528 & 162 & .602 & & \\
total & 98.918 & 164 & & & \\
\hline
\end{tabular}

Table (6) shows that the value of "P" was (1.154) is not statistically significant meaning that there are no statistically significant differences in marital satisfaction due to the variable number of years of marriage.

3-Results related to the third question: Are there differences of statistical significance $(\alpha=0.05)$ in the level of marital satisfaction due to the variable number of children?

To answer this question, the averages and standard deviations of marital satisfaction were extracted according to the number of children variable. Table (7) shows these averages:

Table 7. Averages and standard deviations of marital satisfaction according to the variable number of children

\begin{tabular}{cccc}
\hline Number of children & Number & Average & standard deviations \\
\hline One or less & 26 & 3.48 & .883 \\
From two to three & 56 & 3.29 & .679 \\
four or more & 83 & 3.28 & .806 \\
total & 165 & 3.32 & .777 \\
\hline
\end{tabular}

Table (7) shows the existence of differences in the statistical averages on the scale of marital satisfaction according to the variable number of children. To find out the significance of these differences, a single-variance analysis test was performed. Table (8) shows these results:

Table 8. univariate analysis results to determine the significance of differences, in the scale of marital satisfaction according to the variable number of children

\begin{tabular}{cccccc}
\hline Source of variation & Total squares & Degrees of freedom & Average squares & (P) Value & Level of significance \\
\hline Between groups & .811 & 2 & .405 & .669 & .514 \\
Within groups & 98.107 & 162 & .606 & & \\
total & 98.918 & 164 & & & \\
\hline
\end{tabular}

Table (8) shows that the value of "P" was 0.669 and is not statistically significant, meaning that there are no statistically significant differences in marital satisfaction due to the variable number of children.

4-Results related to the fourth question: Is there a statistically significant $(\alpha=0.05)$ relationship between the work of women and their marital satisfaction?

In order to answer the question about women's work, the frequencies and percentages were extracted and the use of the $\mathrm{chi}^{2}$ test was used to determine the relationship between the work of women and the level of marital satisfaction, as shown in the table (9).

Table 9. Frequency and Percentages and $\mathrm{chi}^{2}$ Test Relationship between levels of marital satisfaction and women's work

\begin{tabular}{|c|c|c|c|c|c|}
\hline Degree of marital satisfaction & Number \& The ratio (\%) & Housewife & Working women & Retired & Total \\
\hline Low grade & number & 15 & 2 & 1 & 18 \\
\hline Low grade & The ratio $(\%)$ & $9.1 \%$ & $1.2 \%$ & $.6 \%$ & $10.9 \%$ \\
\hline Medium degree & number & 64 & 22 & 5 & 91 \\
\hline Medium degree & The ratio $(\%)$ & $38.8 \%$ & $13.3 \%$ & $3.0 \%$ & $55.2 \%$ \\
\hline High degree & number & 36 & 17 & 3 & 56 \\
\hline High degree & The ratio $(\%)$ & $21.8 \%$ & $10.3 \%$ & $1.8 \%$ & $33.9 \%$ \\
\hline
\end{tabular}

chi $^{2=} 2.790 \quad$ Degrees of freedom $=4 \quad$ Statistical significance $=0.594$ 
Table (9) shows that the results of the statistical analysis showed no statistically significant differences in the levels of marital satisfaction between working and non-working women.

5- Results related to the fifth question: Are there differences of statistical significance $(\alpha=0.05)$ in the level of marital satisfaction due to the variable educational level of women?

To answer this question, the averages and standard deviations of marital satisfaction were extracted according to the variable of the educational level of women. Table (10) shows these averages:

Table 10. Averages and standard deviations of marital satisfaction according to the variable educational level of women

\begin{tabular}{cccc}
\hline Educational level & Number & Averages & standard deviation \\
\hline Secondary or lower & 52 & 2.94 & .876 \\
Diploma and Bachelor & 102 & 3.49 & .665 \\
Postgraduate & 11 & 3.52 & .665 \\
\hline
\end{tabular}

Table (10) shows that there are apparent differences in the averages mean on the marital satisfaction scale according to the variable of the educational level of women. In order to determine the significance of these differences, a single-variance analysis test was performed. Table (11) shows these results:

Table 11. Contrast analysis test to find out the significance of differences depending on the educational level of women

\begin{tabular}{cccccc}
\hline Source of variation & Total squares & Degrees of freedom & Average squares & (P) Value & Level of significance \\
\hline Between groups & 10.768 & 2 & 5.384 & 9.895 & .000 \\
Within groups & 88.150 & 162 & .544 & & \\
total & 98.918 & 164 & & & \\
\hline
\end{tabular}

Table (11) shows that the value of "P" was (9.895) its mean there are statistically significant differences in marital satisfaction due to the variable educational level of women, To find out who is the difference, Schefft's Test A post-comparison test was conducted According to the variable level of education for women and the table (12) shows these results:

Table 12. Schefft's test of the post-comparisons in marital satisfaction according to the variable educational level of women

\begin{tabular}{ccc}
\hline Educational level & Diploma and Bachelor & Postgraduate \\
\hline Secondary or lower & $.54587-*$ & -.58343 \\
Diploma and Bachelor & & -0.0375 \\
\hline
\end{tabular}

Table (12) shows statistically significant differences in marital satisfaction according to the variable level of education for women the differences between the same level of public secondary and lower and the campaign of diploma and bachelor and the differences came in favor of the diploma and bachelor that is marital satisfaction is higher than that of the public secondary school or less. The table shows no differences between the other educational levels.

6-Results related to the sixth question: Are there differences of statistical significance $(\alpha=0.05)$ in the level of marital satisfaction due to the variable income of the family?

To answer this question, the arithmetical averages and standard deviations of marital satisfaction were extracted according to the income level variable. Table (13) shows these averages:

Table 13. Averages and standard deviations of marital satisfaction according to the income level variable

\begin{tabular}{cccc}
\hline Income level & Number & Average & standard deviation \\
\hline Less than 500 JD & 57 & 2.99 & .910 \\
From 501 to 1500 JD & 63 & 3.50 & .557 \\
More than 1500 JD & 45 & 3.46 & .743 \\
\hline
\end{tabular}

Table (13) shows that there are apparent differences in the averages on the marital satisfaction scale according to the income level variable, to find out the significance of these differences.

Table 14. The results of the single-variance analysis test to determine the significance of the differences in marital satisfaction according to the income level variable

\begin{tabular}{cccccc}
\hline Source of variation & Total squares & Degrees of freedom & Average squares & (P) Value & Level of significance \\
\hline Between groups & 9.061 & 2 & 4.531 & 8.168 & .000 \\
Within groups & 89.856 & 162 & .555 & & \\
total & 98.918 & 164 & & & \\
\hline
\end{tabular}

Table (14) shows that the "P" value is (8.168), there are statistically significant differences of marital satisfaction due 
to the income level variable, To find out who is the difference, Schefft's Test A post-comparison test was conducted According to the variable of income, table (15) shows the results:

Table 15. Schefft's test of the post-comparisons in marital satisfaction according to the variable income level of women

\begin{tabular}{ccc}
\hline Income level & From 501 to 1500 & More than 1500 \\
\hline Less than 500 & $.50763-^{*}$ & $46959-^{*}$ \\
From 501 to 1500 & & 0.0380 \\
\hline
\end{tabular}

Table (15) shows statistically significant differences in marital satisfaction according to the income level variable, the differences of those with income (501 to 1500), and that is the high level of marital satisfaction.

\section{Discussion}

Several studies have examined marital satisfaction, each study focused on relevant variables, Some studies emphasized on the importance of love in the occurrence of marital satisfaction such as study Carandang \& Guda (2015), Other studies have tested the effect of communication in marital relationships such as study of Abbasi \& Afsharinia (2015), The effect of age on marital satisfaction was also discussed in Dabone (2014), One of the variables studied in relation to marital satisfaction was the Rebello et al study (2014), which found an impact on love, partnership, and jealousy in determining the level of marital satisfaction, while the study by Javanmard \& Garegozlo (2014) showed the role of some personal factors in marital satisfaction, related variables were Villa \& Prette (2013) in Brazil, which dealt with social skills on marital satisfaction, The study of Yadalijamaloye et al (2013) focused on the study of the effect of selfassessment on marital satisfaction, this study sample was large and included only women, Bloch et al (2013) focused on the role of emotional exchange among couples and its impact on the level of marital satisfaction. The study of Zainah et al (2012) also examined the variables of the duration of marriage and income and its impact on levels of marital satisfaction. The current study was characterized by a female sample only, and dealt with many variables: years of marriage, number of children, work of women, educational level, and family income.

This study was similar to the study of Yadalijamaloye et al (2013) since the sample of the study is only women, and similar with the study of Zainah et al (2012) in that it dealt with the study of the variable number of years of marriage and family income and its effect on the level of marital satisfaction, The results of this study indicate the role of both the educational level and the family income in determining the levels of marital satisfaction, and this result is a logical result in line with the culture of the study society.

The educational level of women contributes to the high level of marital satisfaction and explains this through the high level of knowledge among women, which helps in understanding the nature of the marital relationship, and to have the ability to lead marital life and avoid its pitfalls, The level of education may be associated with increased problem-solving capacity, so women's education may be linked to stable marital relationships.

As for family income, it reflects the state of economic stability of the family, the results of the study indicate the role of family income in stabilizing marital status, this may be due to the fact that the level of family income is associated with the welfare of the marital relationship and thus affect the level of marital satisfaction.

The importance of the study is that the society of the study suffers from high divorce rates, and thus may contribute to the study of the risk factors that threaten the stability of marriage, and propose appropriate solutions to address them, in addition to identifying the factors supporting the marital relationship and work on their development.

\section{Recommendation}

-The activation of marriage counseling services for prospective couples may raise levels of marital satisfaction.

-Awareness of the importance of education and its supportive role in the marital relationship, Therefore, community awareness of the importance of education for women and their active role in the success of the marital relationship should be increased

-Preparing continuous training courses for couples about issues related to marital life and dealing with them.

-Awareness of the mechanism of managing the marital relationship within a low family income

-Conducting other studies with different dimensions to learn more about the subject of marital satisfaction.

\section{References}

Abbasi, Farid \& afsharinia, Karim (2015) Relationship between Couples communication Patterns and Marital Satisfaction. International Journal of Economy, Management and Social Sciences, 4(3), 369-372.

Bloch, L., Haase, C. M., \& Levenson, R. W. (2013). Emotion Regulation Predicts Marital Satisfaction:More Than a Wives' Tale. American Psychological Association, 14(1), 130-144.

Carandang, M. N. S., \& Guda, I. V. P. (2015). Indicators of Marital Satisfaction of Batangueño Couples: Components of Love and the Other External Factors in Marriage. International Journal of Information and Education Technology, 5(1). https://doi.org/10.7763/IJIET.2015.V5.477

Dabone, K. T. (2014). Effects of Age on Marital Satisfaction of Married People in Sunyani Municipality. International Journal of Research in Social Sciences, 3(8). 
Hartley Sigan L., Barker Erin T., Seltzer Marsha Mailick, Greenberg Jan S. \& Frank J. Floyd. Marital Satisfaction and Parenting Experiences of Mothers and Fathers of Adolescents and Adults with Autism. American Association on Intellectual and Developmental Disabilities, 116(1), 81-95.

Javanmard, G. H., \& Garegozlo, R. M. (2014). The Study of Relationship between Marital Satisfaction and Personality Characteristics in Iranian Families. Procedia-Social and Behavioral science, 84(9), July 2013, 396-399. The 3rd World Conference on Psychology, Counseling and Guidance, WCPCG-2012.

Rebello, K., Junior, M. D. S., \& Brito, R. C. S. (2014). Fundamental Factors in Marital Satisfaction. Psychology, 5, 777-784, Published Online May 2014 inSci Res. http://dx.doi.org/10.4236/psych.2014.57088.

Tianyuan, Li, \& Helene, H, Fung. (2011). The Dynamic Goal Theory of Marital Satisfaction. Review of General Psychology, 15(3), 246-254. https://doi.org/10.1037/a0024694

Villa, M, B., \& Del Prette, Z., Aparecida Pereira (2013) Marital Satisfaction: The Role of Social Skills of Husbands and Wives. Paidéia, sep-dec., 23(56), 379-387. https://doi.org/10.1590/1982-43272356201312

Yadalijamaloye, Z., Naseri, E., Shoshtari, M., Khaledian, M., \& Ahram, R. (2013). Relationships between self-esteem and marital satisfaction women. Psychology and Behavioral Sciences, 2(3), 124-129. https://doi.org/10.11648/j.pbs.20130203.17

Zainah, A. Z., Nasir, R., Hashim, R. S., \& Yusof, N. M. (2012). Effects of Demographic Variables on Marital Satisfaction. Asian Social Science, 8(9).

\section{Martial Satisfaction Scale}

\begin{tabular}{|c|c|c|c|c|c|c|}
\hline Number & Paragraph & $\begin{array}{l}\text { Very low } \\
\text { degree }\end{array}$ & $\begin{array}{c}\text { A few } \\
\text { degrees }\end{array}$ & $\begin{array}{c}\text { Medium } \\
\text { degree }\end{array}$ & $\begin{array}{l}\text { Great } \\
\text { degree }\end{array}$ & $\begin{array}{l}\text { Very large } \\
\text { degree }\end{array}$ \\
\hline 1. & I feel comfortable with my husband & & & & & \\
\hline 2. & $\begin{array}{l}\text { Understanding is the basis of the dealings between me and } \\
\text { my husband }\end{array}$ & & & & & \\
\hline 3. & My personal relationship with my husband is warm & & & & & \\
\hline 4. & My relationship with my husband achieved social support & & & & & \\
\hline 5. & $\begin{array}{l}\text { I progress socially / professionally as a result of my } \\
\text { husband's support for me }\end{array}$ & & & & & \\
\hline 6. & $\begin{array}{l}\text { My husband encourages me to strengthen my relationships } \\
\text { with my friends }\end{array}$ & & & & & \\
\hline 7. & My husband supports a relationships with my family & & & & & \\
\hline 8. & My husband helps me in the housework & & & & & \\
\hline 9. & $\begin{array}{l}\text { I often agreed with my husband on how to deal with } \\
\text { children }\end{array}$ & & & & & \\
\hline 10. & I share with my husband recreational activities & & & & & \\
\hline 11. & $\begin{array}{l}\text { My relationship with my husband is more peaceful than the } \\
\text { conflict }\end{array}$ & & & & & \\
\hline 12. & My husband looks like a lot of things to me & & & & & \\
\hline 13. & I get my husband's sympathy with me when I get sick & & & & & \\
\hline 14. & My husband deals positively if I make a mistake & & & & & \\
\hline 15. & I touch the state of constant tolerance by my husband & & & & & \\
\hline 16. & $\begin{array}{l}\text { The most support I get in my social relationships is my } \\
\text { husband's support }\end{array}$ & & & & & \\
\hline 17. & When my husband and I disagree, we resort to dialogue & & & & & \\
\hline 18. & My husband and I exchanged courtesy & & & & & \\
\hline 19. & $\begin{array}{l}\text { My husband has qualities that fill the gaps that I suffer } \\
\text { from }\end{array}$ & & & & & \\
\hline 20. & My husband appreciates the work I do & & & & & \\
\hline
\end{tabular}

\section{Copyrights}

Copyright for this article is retained by the author(s), with first publication rights granted to the journal.

This is an open-access article distributed under the terms and conditions of the Creative Commons Attribution license (http://creativecommons.org/licenses/by/4.0/). 